\title{
Association of EMP1 with gastric carcinoma invasion, survival and prognosis
}

\author{
GUOGUI SUN ${ }^{1}$, GANG ZHAO $^{2}$, YIFANG LU $^{3}$, YADI WANG ${ }^{4}$ and CONGRONG YANG ${ }^{5}$ \\ ${ }^{1}$ Department of Chemoradiotherapy, Tangshan People's Hospital; ${ }^{2}$ Department of Gastrointestinal Surgery, \\ The Second Tangshan Hospital; ${ }^{3}$ Department of Endocrinology, Tangshan Workers Hospital, Tangshan 063000; \\ ${ }^{4}$ Department of Radiotherapy, The Military General Hospital of Beijing PLA, Beijing 100700; \\ ${ }^{5}$ Department of Radiotherapy, The Fourth Hospital of Hebei Medical University, \\ Shijiazhuang 050017, P.R. China
}

Received February 27, 2014; Accepted April 19, 2014

DOI: $10.3892 / \mathrm{ijo} .2014 .2488$

\begin{abstract}
The aim of this study was to determine the expression and function of epithelial membrane protein 1 (EMP1) in gastric carcinoma. Gastric samples were taken from cancer lesions and adjacent normal tissue in gastric cancer patients immediately after endoscopic biopsy. A portion of the sample was either fixed in $4 \%$ paraformaldehyde and embedded in paraffin for immunohistochemistry or stored in liquid nitrogen for western blotting. In order to determine protein expression of EMP1 in gastric cancer $(n=65)$ and normal tissue $(n=27)$, semi-quantitative immunohistochemistry and western blotting were utilized. For in vitro studies, the human gastric cancer cell line SGC-7901 was maintained in RPMI-1640 medium supplemented with $10 \%$ fetal bovine serum. Recombinant lentivirus mediated overexpression of EMP1 in SGC-7901 cells was quantified with quantitative polymerase chain reaction (qPCR) and western blotting. Control SGC-7901 cells were transfected with an empty vector. To further study the effect of EMP1 overexpression in SGC-7901 cells, cell proliferation, cell apoptosis and migration and invasion assays were conducted. The expression of EMP1 was significantly lower in gastric cancer tissue compared to normal tissue using both immunohistochemistry ( 41.5 vs. $70.4 \%$ of tissues, $\mathrm{P}<0.05$ ) and western blotting $(0.153 \pm 0.012$ vs. $0.626 \pm 0.058, \mathrm{P}<0.05)$. Decreased expression of EMP1 was significantly correlated with tumor invasion, lymph node metastasis, clinical stage and histological grade of patients with gastric cancer $(\mathrm{P}<0.05)$. According to Kaplan-Meier analysis, low EMP1 expression correlated significantly with poor overall 5-year survival (47.4
\end{abstract}

Correspondence to: Professor Gang Zhao, Department of Gastrointestinal Surgery, The Second Tangshan Hospital, No. 21 Jianshen Road, Lubei, Tangshan, Hebei 063000, P.R. China

E-mail: gang_zhao2014@163.com

Key words: epithelial membrane protein 1, gastric carcinoma, caspase-9, VEGFC, metastasis, prognosis vs. $70.3 \%$ survival, $\mathrm{P}<0.05)$. SGC-7901 cells transfected with EMP1 had a lower survival fraction, higher cell apoptosis $(13.2 \pm 1.5 \%$ vs. $2.2 \pm 0.5 \%, \mathrm{P}<0.05)$, significant decrease in migration and invasion $(157.0 \pm 16.0$ and $112.0 \pm 12.0$, respectively vs. $243.0 \pm 21.0$ and $203.0 \pm 19.0$, respectively, $\mathrm{P}<0.05$ ), higher caspase- $9(0.501 \pm 0.050$ vs. $0.114 \pm 0.010, \mathrm{P}<0.05)$ and lower VEGFC protein expression $0.135 \pm 0.011$ vs. $0.619 \pm 0.074$, $\mathrm{P}<0.05)$ relative to cells not transfected with EMP1. Low EMP1 expression in gastric cancer is associated with increased disease severity, suggesting that EMP1 may be a negative regulator of gastric cancer.

\section{Introduction}

The incidence and mortality of gastric cancer have fallen dramatically in USA and elsewhere over the past several decades. Nonetheless, gastric cancer remains a major public health issue as the fourth most common cancer and the second leading cause of cancer death worldwide. For the past few decades, gastric cancer mortality has decreased markedly in most areas of the world (1). However, gastric cancer remains a disease of poor prognosis and high mortality, second only to lung cancer as the leading cause of cancer-related death worldwide. Gastric cancer is a multifactorial disease. The marked geographic variation, time trends and the migratory effect on gastric cancer incidence suggest that environmental or lifestyle factors are major contributors to the etiology of this disease (2). The well-established histopathological factors that influence disease outcome are tumor size, histological type and subtype, the presence of signet ring morphology, the degree of differentiation, the presence of lymphovascular invasion and lymph node involvement $(3,4)$. Further understanding of the molecular mechanisms underlying the pathophysiology of metastatic processes will not only help us to identify those patients at greatest risk of recurrence but also find novel molecular targets for the development of treatment strategies for gastric cancer. A preliminary study on the epithelial membrane protein 1 (EMP1) gene found that EMP1 is closely linked to tumor development and progression $(5,6)$. Activation of the EMP1 gene in particular can prevent tumor proliferation, 
and it may be a new target for tumor therapy $(7,8)$. However, to date there is no information available regarding the relationship between EMP1 and gastric cancer. We studied EMP1 expression in gastric cancer using immunohistochemistry and western blot and analyzed the effect of EMP1 overexpression in vitro in the gastric cancer cell line SGC-7901 $(9,10)$.

\section{Materials and methods}

Clinical data. All patients enrolled in this study provided informed consent in advance. There were 39 males and 26 females, aged from 21 to 78 years old, with a median age of 54 years. Of the 65 cases of gastric cancer, 31 had T1 and T2 stage cancers and 34 had T3 and T4 stage cancer. Twentyseven patients presented with no lymph node metastasis (N0), whereas 38 presented with identified lymph node involvement $(\mathrm{N}+)$. As for the clinical stage, 28 cases had stage I-II gastric cancers and 37 had stage III-IV gastric cancer. Regarding grade of differentiation, 29 had Grade I (well differentiated) tumors and 36 had Grade II or III (moderately to poorly differentiated) tumors. Samples were taken immediately after the endoscopic biopsy, and either fixed in 4\% paraformaldehyde solution and embedded in paraffin for immunohistochemistry or stored in liquid nitrogen for western blot analysis.

Cell culture and gene transfection. Human gastric cancer SGC-7901 cells were maintained in RPMI-1640 medium (Gibco BRL, Carlsbad, CA, USA) supplemented with $10 \%$ fetal bovine serum (Gibco BRL). Medium was changed every 2-3 days; when the cultures reached confluence, the cells were subcultured with $0.25 \%$ trypsin and $1 \%$ ethylene diaminetetraacetic acid (EDTA). Cells were tested every 3 months for mycoplasma and mycoplasma removal agent (MRA) (MP Biomedicals Co., Ltd., Shanghai, China) was used to maintain mycoplasma-free cultures. EMP1 cDNA was cloned into the BamHI and AscI sites of the plenti6/V5-DEST vector (Invitrogen, Carlsbad, CA, USA). After amplification and DNA sequence confirmation, this vector was used to overexpress EMP1 in SGC-7901 cells. Briefly, SGC-7901 cells were grown and stably transfected with pLenti6-EMP1 or plenti6/V5-DEST for control using Lipofectamine 2000 (Invitrogen) and grown in Blastidicin $(5 \mu \mathrm{g} / \mathrm{ml})$-containing RPMI-1640 medium.

Immunohistochemistry. Immunohistochemistry was performed as previously described (11). Briefly, 4- $\mu \mathrm{m}$ sections were prepared from a paraffin-embedded block and dehydrated, incubated in 3\% hydrogen peroxide for $10 \mathrm{~min}$ and incubated in trypsin for $20 \mathrm{~min}$. Sections were blocked with $10 \%$ goat serum at room temperature for $20 \mathrm{~min}$ and treated with rabbit anti-human EMP1 polyclonal antibody (1:100; Abcam, Cambridge, UK) overnight at $4^{\circ} \mathrm{C}$. After rinsing, sections were treated with biotin-conjugated antibodies (4A Biotech Co., Ltd., Beijing, China) for $20 \mathrm{~min}$, and biotin-immune complexes were identified with a diaminobenzidine (DAB) substrate immunochemistry kit (4A Biotech Co., Ltd.) and hematoxylin stain. Sections were mounted and dehydrated with the coverslip sealed. For the negative control, sections were treated identically except primary antibody was replaced with PBS. Two pathologists blinded to patient and tissue status assessed the results. Three slides for each specimen were counted, with five fields of view randomly selected for evaluation per section. EMP1 expression level was based on the percentage of positive cells and staining intensity. The percentage of positive cells was divided into four levels: 0 points, $\leq 5 \%$ of positive cells; 1 point, $5-25 \%$; 2 points, $25-50 \%$; and 3 points, $>50 \%$. The intensity of staining was classified as: 0 points, no staining; 1 point, weak staining (light yellow); 2 points, moderate staining (yellowish-brown); and 3 points, strong staining (brown). The final score of EMP1 expression was the product of the EMP1 expression rate (percentage score) and intensity: - for 0 points, + to +++ for positive (+ for 1-3 points, ++ for 4-6 points and +++ for $7-9$ points).

Quantitative real-time $(q)$ reverse transcription $(R T)-P C R$. Total RNA was extracted from SGC-7901 cells using TRIzol reagent (Invitrogen) according to the manufacturer's protocol (12). Total RNA (500 ng) was reverse transcribed using Takara Reverse Transcriptase Reagents (Takara, Shiga, Japan). qRT-PCR was performed with an ABI PRISM 7300 (Applied Biosystems, Inc., Carlsbad, CA, USA) according to the standard protocol for SYBR-Premix ExTaq (Perfect Real-Time; Takara). Primers for EMP1 and $\beta$-actin for normalization were as follows: EMP1 sense 5'-CCCTCCTGGTCTTCGTGT, antisense 5'-AATAGCCGTGGTGATA; $\beta$-actin sense 5'-ATC GTCCACCGCAAATGCTTCTA, antisense 5'-AGCCAT GCCAATCTCATCTTGTT. Thermal cycling conditions were $95^{\circ} \mathrm{C}$ for $1 \mathrm{~min}, 95^{\circ} \mathrm{C}$ for $15 \mathrm{sec}$ and 40 cycles at $60^{\circ} \mathrm{C}$ for $1 \mathrm{~min}$. The relative expression was calculated using the $2^{-\Delta \Delta C t}$ method in SDS 1.3 software (Applied Biosystems, Inc.).

Western blot analysis. Western blot was performed as previously described (13). Samples were lysed in lysis buffer containing $1 \%$ NP-40, $0.1 \%$ SDS, $25 \mathrm{mmol} / 1$ HEPES, $134 \mathrm{mmol} / \mathrm{l} \mathrm{NaCl}, 1 \mathrm{mmol} / \mathrm{l}$ vanadate, $100 \mathrm{mmol} / \mathrm{l} \mathrm{NaF}$ and $0.5 \%$ Na-deoxycholate. After centrifugation at $12000 \mathrm{r} / \mathrm{min}$ for $20 \mathrm{~min}$ at $4^{\circ} \mathrm{C}$, the supernatant was stored at $-20^{\circ} \mathrm{C}$. Protein concentration was detected with the BCA Protein Assay kit (Tiangen Biotech Co., Ltd., Beijing, China). Protein $(50 \mathrm{mg}$ ) was resolved on a $10 \%$ SDS-PAGE and transferred to nitrocellulose membrane. For EMP1, blots were blocked for $2 \mathrm{~h}$ with $5 \%$ skim milk and incubated overnight at $4{ }^{\circ} \mathrm{C}$ with rabbit anti-human EMP1 (1:1000), caspase-9 (1:1000; Abcam) and VEGFC (1:1000; Abcam). For $\beta$-actin, blots were blocked in $5 \%$ non-fat dry milk for $1 \mathrm{~h}$ at room temperature and incubated overnight in mouse anti- $\beta$-actin (Sigma, St. Louis, MO, USA) overnight at $4^{\circ} \mathrm{C}$. After washing, membranes were either incubated with goat anti-mouse fluorescent secondary antibody (1:20000; IRDye800, LI-COR Bioscience, Inc., Lincoln, NE, USA) or DyLight Fluor conjugated goat anti-rabbit secondary antibody (LI-COR Bioscience, Inc.) in the dark for $1 \mathrm{~h}$ at room temperature. The blots were scanned and analyzed using the Odyssey Infrared Imaging System (LI-COR Bioscience, Inc.). Western blot data were quantified by normalizing the signal intensity of each sample to that of $\beta$-actin (13).

MTT assay. Cell viability was determined using the tetrazolium salt MTT [3-(4,5-dimethylthiazol-2-yl)-2,5-diphenyltetrazolium bromide] assay, as previously described (14). Briefly, cells were plated into 96-well culture plates at an optimal density of 


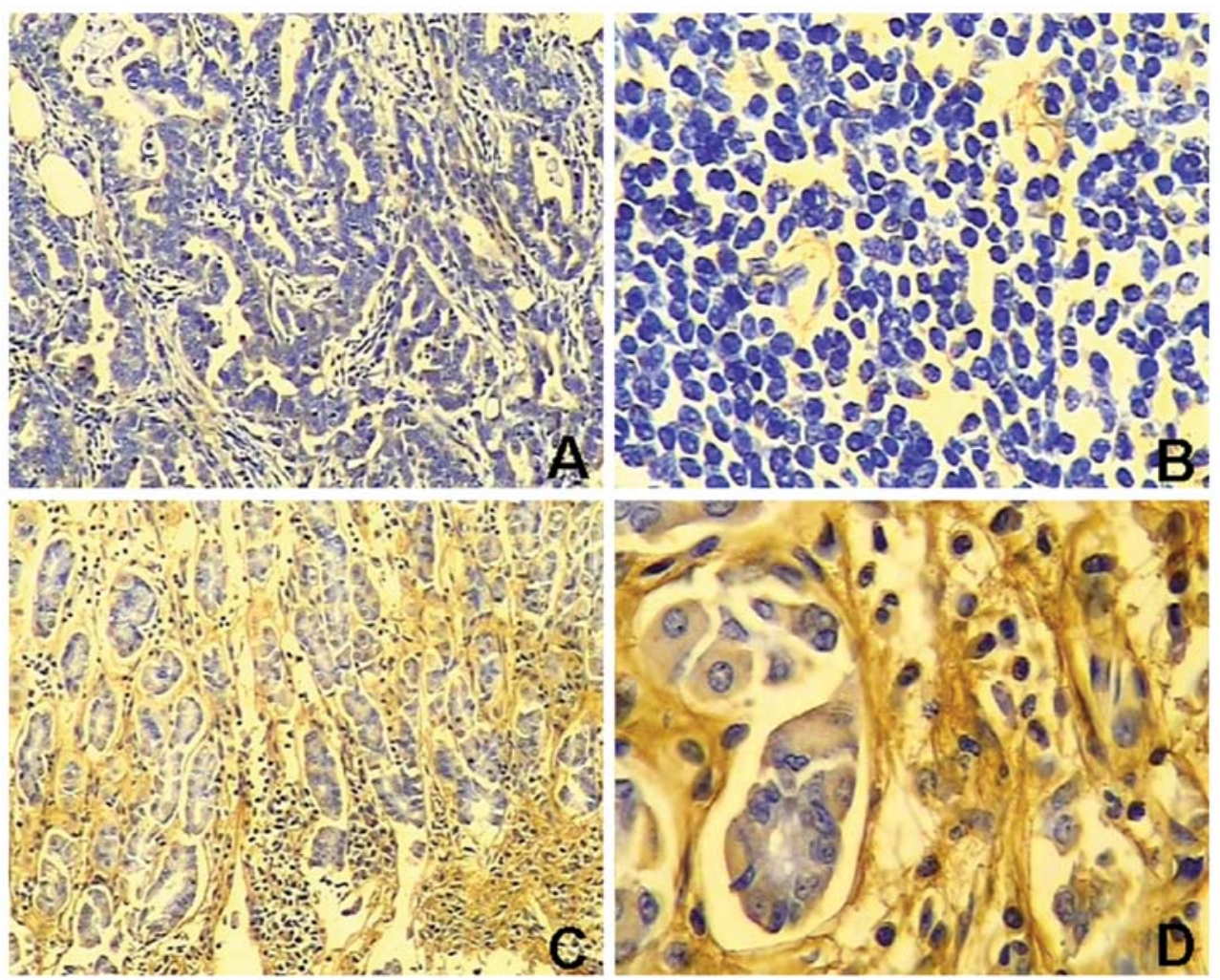

Figure 1. Immunohistochemistry of EMP1 protein in gastric carcinoma and adjacent normal tissue. (A and B) Representative sample of gastric carcinoma [(A) SP x100, (B) SP x400]. There is little staining for EMP1; (C and D) normal gastric tissue [(C) SP x100, (D) SP x400]. There is intense yellow and yellow-brown staining of EMP1.

$5 \times 10^{3}$ cells $/ \mathrm{ml}$ in $200 \mu \mathrm{l}$ of culture medium/well. After $24-96 \mathrm{~h}$ of culture, $20 \mu 1$ of $5 \mathrm{mg} / \mathrm{ml}$ MTT was added to each well and incubated at $37^{\circ} \mathrm{C}$ for $4 \mathrm{~h}$. The medium was then gently aspirated and $150 \mu 1$ of dimethyl sulfoxide (DMSO) was added to each well to solubilize the formazan crystals. The optical density of each sample was immediately measured using a microplate reader (Bio-Rad, Hercules, CA, USA) at $570 \mathrm{~nm}$.

Flow cytometry assay. An Annexin V-FITC-flow cytometry assay (4A Biotech Co., Ltd.) was used to detect the apoptosis rate in the cells after EMP1 transfection, as previously described (15). Cells were seeded into $60-\mathrm{mm}$ dishes for $48 \mathrm{~h}$ and grown to $70-75 \%$ confluence. After quick detachment from the plate, cells were collected, washed with ice-cold PBS, and resuspended at a cell density of $1 \times 10^{6} / \mathrm{ml}$ in a binding buffer from the Annexin V-FITC apoptosis detection kit (4A Biotech Co., Ltd.). Cells were then stained with $5 \mu \mathrm{l}$ of Annexin V-FITC and $10 \mu 1$ of propidium iodide (PI, $20 \mu \mathrm{g} / \mathrm{ml}$ ). The cells were incubated in the dark at $25^{\circ} \mathrm{C}$ for $15 \mathrm{~min}$ before 10,000 cells were analyzed by a FACScan flow cytometer (BD Immunocytometry Systems, San Jose, CA, USA) and Cellquest software (BD Immunocytometry Systems) for apoptosis rate determination.

Invasion and migration assays. Invasion and migration assays were performed as previously described (16). For the invasion assay, Costar Transwell $8 \mu \mathrm{m}$ inserts were coated with $50 \mu \mathrm{g}$ reduced serum Matrigel (BD Biosciences, Bedford, MA, USA). Invasion Chambers (BD China, Shanghai, China) were coated with Matrigel and 7x10 cells were added per chamber. Medium supplemented with 10\% FBS was used in the lower chamber. For migration assays, the same procedure was used excluding the Matrigel. After $12 \mathrm{~h}$, non-invading cells and media were removed, and cells on the lower surface of the membrane were fixed with polyoxymethylene (Sigma) and stained with $0.1 \%$ crystal violet (Sigma) for $0.5 \mathrm{~h}$. Stained cells were counted under a microscope in four randomly selected fields, and the average was used to indicate cell migration and invasion.

Statistical analysis. All statistical analyses were performed using SPSS 16.0 software (IBM, Chicago, IL, USA), as previously described (17). For the clinicopathological features, P-values were calculated using the $\chi^{2}$ test. Student's t-test was used to analyze the difference between groups. Survival distributions were estimated with the Kaplan-Meier method and compared with the log-rank test. A P-value $<0.05$ was considered to be statistically significant.

\section{Results}

EMP1 protein expression in gastric cancer and normal tissues. EMP1 staining in gastric cancer tissue was negative or weak relative to normal adjacent gastric tissues that exhibited light yellow to brown staining. EMP1 expression was significantly lower $(\mathrm{P}<0.05)$ in gastric cancer tissue (expressed in $41.5 \%, 27 / 65)$ than normal tissue (expressed in 70.4\%, 19/27) (Table I, Fig. 1). Western blot analysis showed that the expression of EMP1 
Table I. Expression of EMP1 in gastric cancer tissue and normal tissue.

\begin{tabular}{lrrrrrrrr}
\hline & & \multicolumn{6}{c}{ Expression of EMP1 protein } \\
\cline { 3 - 8 } Groups & Case & - & + & ++ & +++ & $\chi^{2}$ & P-value \\
\hline Normal tissue & 27 & 8 & 4 & 7 & 8 & 9.587 & 0.022 \\
Cancer tissue & 65 & 38 & 11 & 10 & 6 & &
\end{tabular}

Table II. Relationship between EMP1 expression and clinical characteristics in gastric cancer tissue.

\begin{tabular}{lccccc}
\hline & \multicolumn{5}{c}{ Expression of EMP1 protein } \\
\cline { 2 - 6 } Groups & Case & - & + to +++ & $\chi^{2}$ & P-value \\
\hline Tumor invasion & & & & & \\
T1+T2 & 31 & 21 & 20 & 6.412 & 0.011 \\
T3+T4 & 34 & 27 & 7 & & \\
Clinical stages & & & & & \\
I-II & 28 & 11 & 17 & 4.800 & 0.028 \\
III-IV & 37 & 27 & 10 & & \\
Histological grade & & & & & \\
III & 29 & 10 & 19 & 4.593 & 0.032 \\
I-II & 36 & 27 & 8 & & \\
Lymph node & & & & & \\
metastasis & & & & & \\
N0 & 27 & 11 & 16 & 5.972 & 0.015 \\
N+ & 38 & 27 & 11 & & \\
\hline
\end{tabular}

in cancer lesions was significantly less than adjacent normal tissue $(0.153 \pm 0.012$ and $0.626 \pm 0.058$, respectively; $\mathrm{P}<0.05)$ (Fig. 2). The expression of EMP1 negatively correlated with tumor invasion, lymph node metastasis, clinical stages and pathological differentiation $(\mathrm{P}<0.05$, Table II).

EMP1 expression and prognosis. Patients were followed up for 60 months for survival analysis. At the end of the study in 2013, 37 of 63 patients had survived. Patients were divided into two groups according to expression level of EMP1. Of the 27 patients with positive levels of EMP1 expression, 19 were still alive, yielding a survival rate of $70.3 \%$. Of the 38 patients with undetectable levels of EMP1 expression, only 18 were still alive, yielding a survival rate of $47.4 \%$. Patients with high levels of EMP1 had a significantly higher 5-year survival rate than those with low levels of EMP1 $(\mathrm{P}<0.05)$ (Fig. 3).

Stable transfection of EMP1 cDNA in gastric cancer cells. SGC-7901 cells stably transfected with EMP1 overexpressed EMP1 (named as LeEMP1 cells). Control SGC-7901 cells were transfected with an empty vector (named as LeEmpty cells). The expression of EMP1 mRNA and protein was significantly elevated in LeEMP1 cells relative to control cells $(\mathrm{P}<0.05)$.
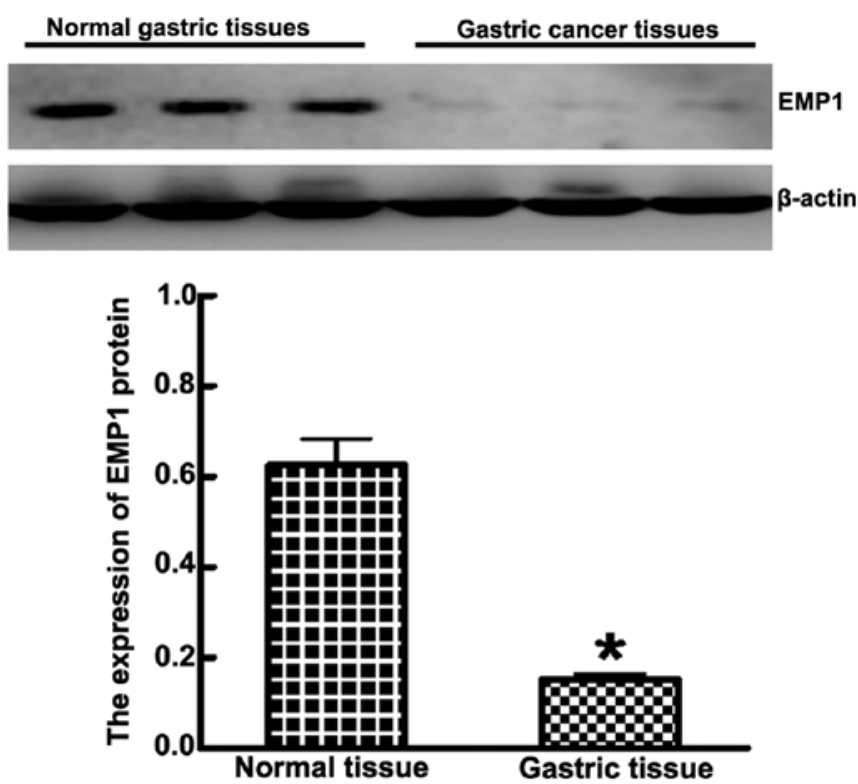

Figure 2. EMP1 protein in gastric carcinoma and normal tissue detected by western blot analysis. Upper panel, representative blots of normal (left) and cancer gastric (right) tissue. Lower panel, summary of all samples. EMP1 levels are significantly less in gastric cancer relative to control. ${ }^{*} \mathrm{P}<0.05$.

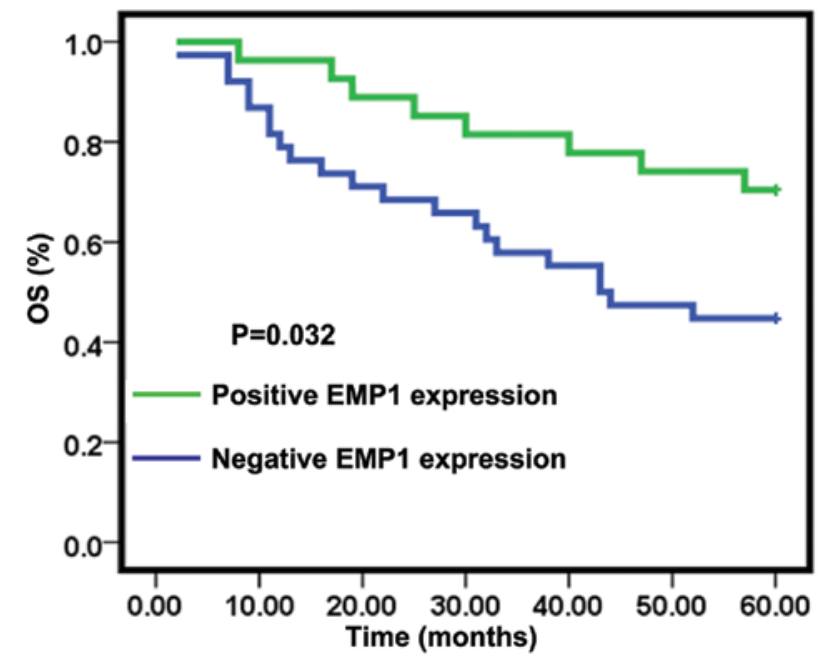

Figure 3. Relationship between EMP1 expression and 10-year survival in gastric carcinoma by Kaplan-Meier analysis. Overall survival is higher in EMP1-positive patients relative to EMP1-negative patients $(\mathrm{P}<0.05)$.

EMP1 mRNA levels detected by RT-PCR was significantly higher in LeEMP1 cells $(0.626 \pm 0.058)$ than LeEmpty cells $(0.188 \pm 0.018)(\mathrm{P}<0.05$; Fig. 4A). Western blot analysis found that the level of immunoreactive protein was significantly higher in EMP1 transfected cells $(0.731 \pm 0.070)$ relative to controls cells $(0.244 \pm 0.019)(\mathrm{P}<0.05$; Fig. 4B).

Effects of EMP1 overexpression on gastric cancer cells. Next, we assessed the effect of EMP1 expression on the regulation of gastric cancer cell viability. MTT assay showed that relative proliferative capacity of LeEMP1 cells grew significantly slower at 24, 48, 72 and $96 \mathrm{~h}$ relative to LeEmpty cells $(\mathrm{P}<0.05$; 

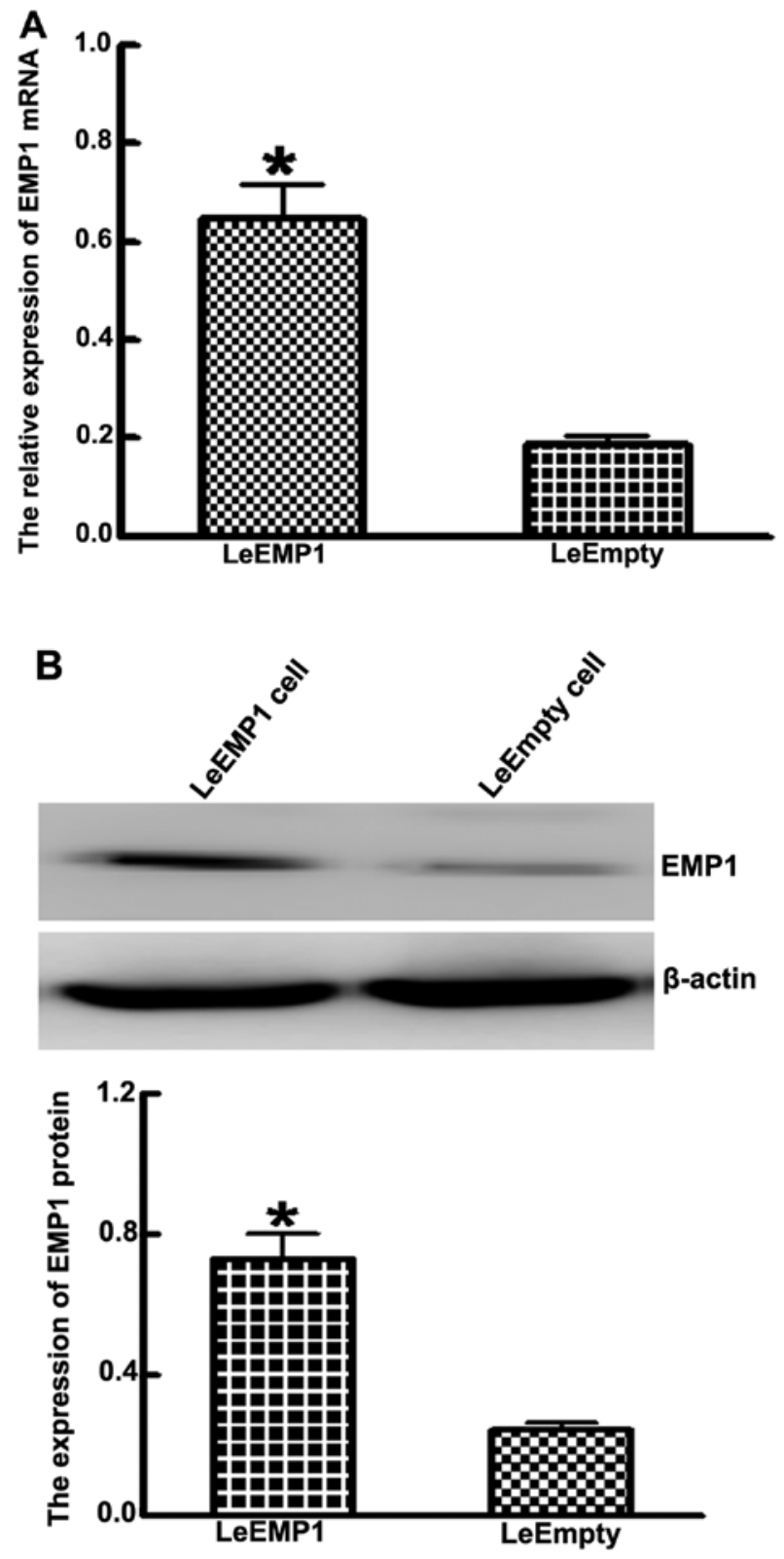

Figure 4. Expression and identification of the EMP1 gene. (A) RT-PCR for EMP1 in LeEmpty cells vs. LeEMP1 cells; (B) Sample western blots for EMP1 and actin (loading control) in LeEmpty and LeEMP1 cells (top). Summary of western blot data for EMP1 protein expression (bottom). ${ }^{*} \mathrm{P}<0.05$.

Fig. 5). Meanwhile, there was a significant increase in the early apoptosis rate in LeEMP1 cells $(13.2 \pm 1.5 \%)$ relative to control cells $(2.2 \pm 0.5 \%)(\mathrm{P}<0.05$; Fig. 6). SGC-7901 cells transfected with EMP1 or empty vector were transferred to transwell chambers or Matrigel-coated transwell chambers to evaluate the effect of EMP1 on cell invasion potential. Overexpression of EMP1 clearly significantly decreased cell migration and invasion of SGC-7901 cells $(157.0 \pm 16.0$ and $112.0 \pm 12.0$, respectively) relative to control cells $(243.0 \pm 21.0$ and 203.0 \pm 19.0 , respectively) $(\mathrm{P}<0.05$; Fig. 7).

To further study the mechanisms by which EMP1 inhibited gastric cancer cell proliferation, cell apoptosis, migration and invasion, we analyzed the expression of two proteins with critical roles in these processes, caspase-9 and VEGFC. Western blot analysis revealed that overexpression of EMP1

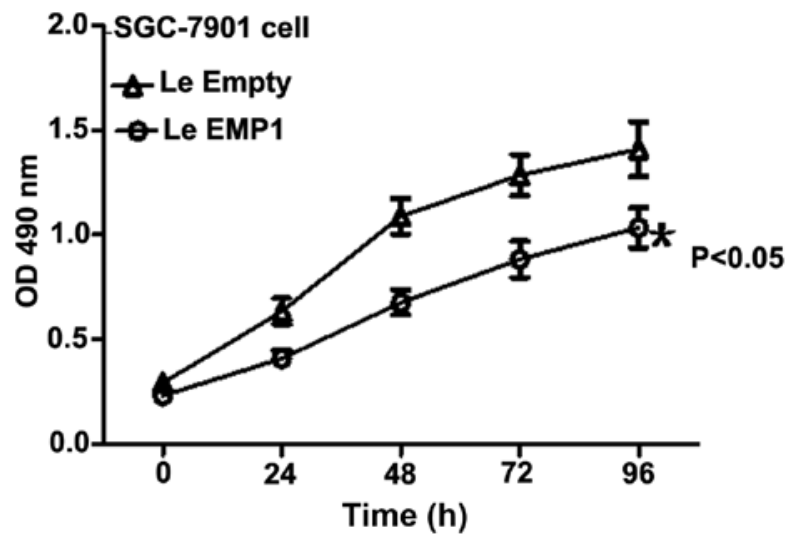

Figure 5. Effects of EMP1 overexpression on cell proliferation. MTT assay time-course for LeEmpty and LeEMP1 cells. Cells overexpressing EMP1 have a significantly decreased rate of proliferation relative to control cells. ${ }^{*} \mathrm{P}<0.05$.

in SGC-7901 cells significantly upregulated caspase-9 protein expression $(0.501 \pm 0.050)$ relative to control cells $(0.114 \pm 0.010)$ ( $\mathrm{P}<0.05$; Fig. 8). In contrast, the level of VEGFC protein expression was significantly lower in SGC-7901 cells overexpressing EMP1 $(0.135 \pm 0.011)$ than control cells $(0.619 \pm 0.074)(\mathrm{P}<0.05$; Fig. 8).

\section{Discussion}

Several studies have shown that the EMP1 gene is expressed in a number of normal tissues $(7,18-23)$. In this study, we localized and quantified for the first time EMP1 protein expression in gastric cancer tissue and normal gastric tissue using immunohistochemistry and immunoblotting. EMP1 protein levels were significantly lower in gastric carcinoma than in normal tissue and EMP1 protein levels correlated with tumor invasion, lymph node metastasis and clinical stage of gastric cancer. Since dedifferentiation is a hallmark of tumor cells, our findings suggest that a decline in EMP1 level is a factor in the development and progression of gastric cancer. In a study evaluating several types of human breast cancer cells with different metastatic characteristics, EMP1 gene expression was correlated with cell invasion and other properties of metastasis (24). EMP1 gene expression was downregulated in oral squamous cell carcinoma and this downregulation was correlated with lymph node metastasis (25). Therefore, the EMP1 gene may be an important factor for the regulation of cell signaling, cell communication and adhesion (26).

Currently an effective treatment paradigm for gastric cancer is surgical extended lesion resection, accompanied by chemotherapy and/or radiotherapy before and after surgery. However, the survival rate with this strategy is not very satisfactory $(27,28)$. Therefore, efforts should be directed toward early detection of gastric cancer and the refinement of individual-based treatment strategies. Conventional treatment and prognosis of gastric cancer rely mainly on TNM classification (29). This system is subjective and not informative for early gastric cancer, and offers limited information on the disease severity, prognosis and response to treatment. Early detection of gastric cancer is the most effective way to improve survival (30). Using survival analysis, we found that EMP1 expression- 

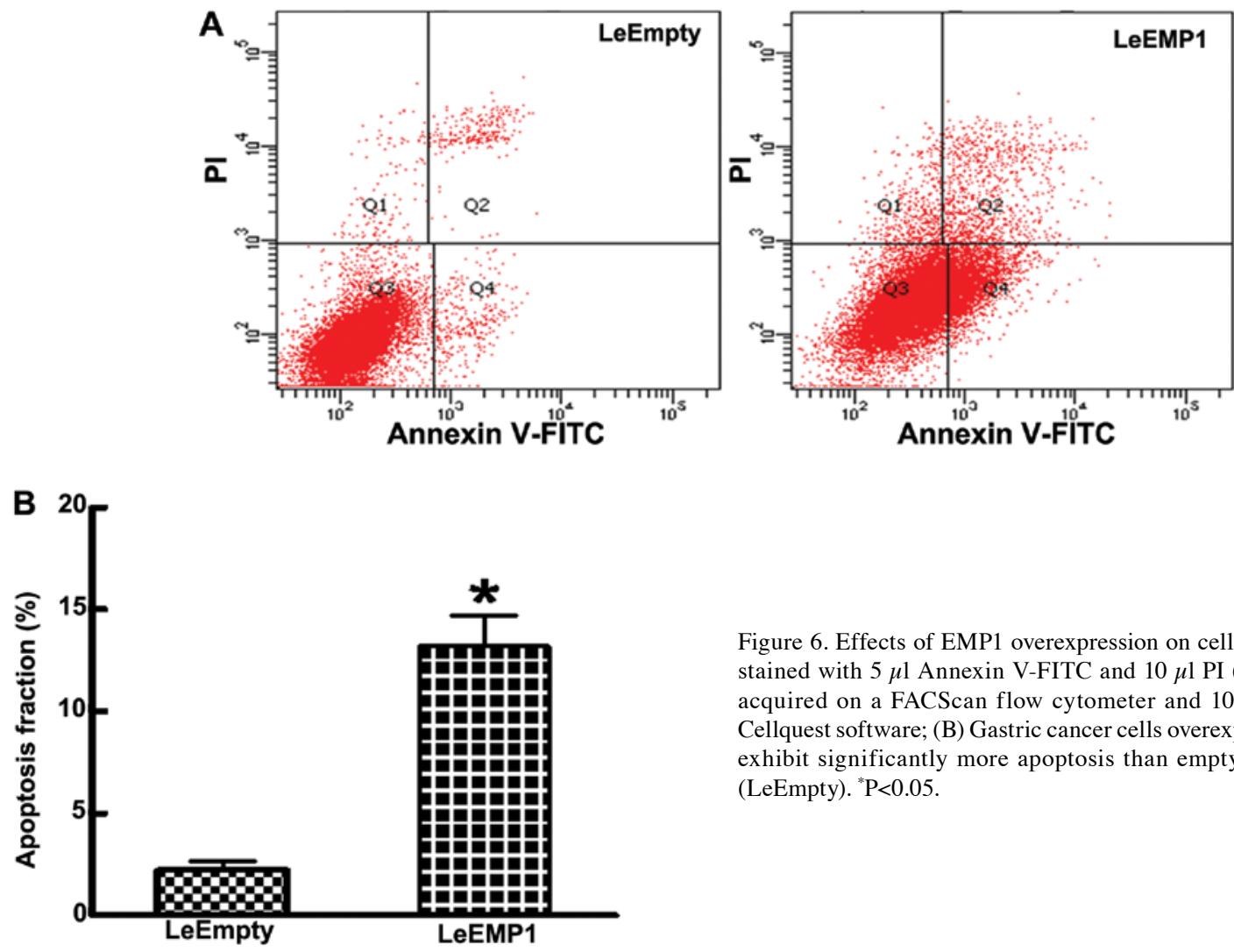

Figure 6. Effects of EMP1 overexpression on cell apoptosis. (A) Cells were stained with $5 \mu 1$ Annexin V-FITC and $10 \mu 1 \mathrm{PI}(20 \mu \mathrm{g} / \mathrm{ml})$. Samples were acquired on a FACScan flow cytometer and 10,000 cells analyzed with Cellquest software; (B) Gastric cancer cells overexpressing EMP1 (LeEMP1) exhibit significantly more apoptosis than empty vector transfected cells (LeEmpty). ${ }^{*} \mathrm{P}<0.05$.
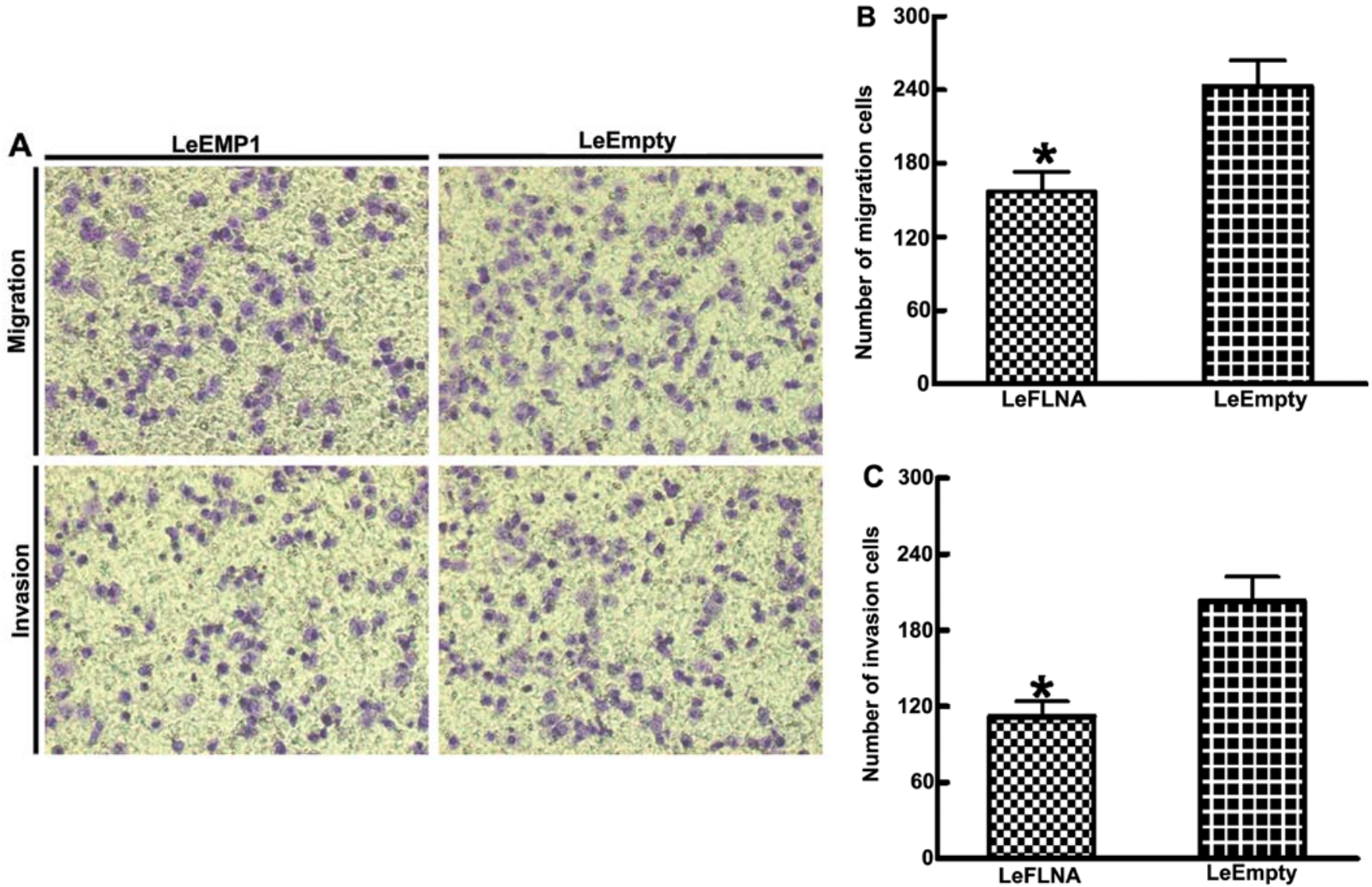

Figure 7. Effects of EMP1 overexpression on cell migration and invasion. (A) Histological sections of cell migration and invasion in LeEmpty and LeEMP1 cells; (B) The number of migrating cells is significantly greater in LeEmpty cells than LeEMP1 cells; (C) Number of invading cells is greater in LeEmpty than LeEMP1 transfected cells. "P $<0.05$. 
A
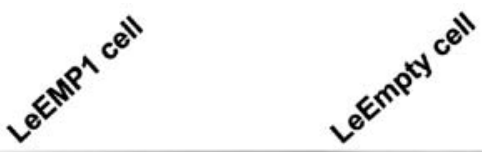

Caspase-9

$\beta$-actin
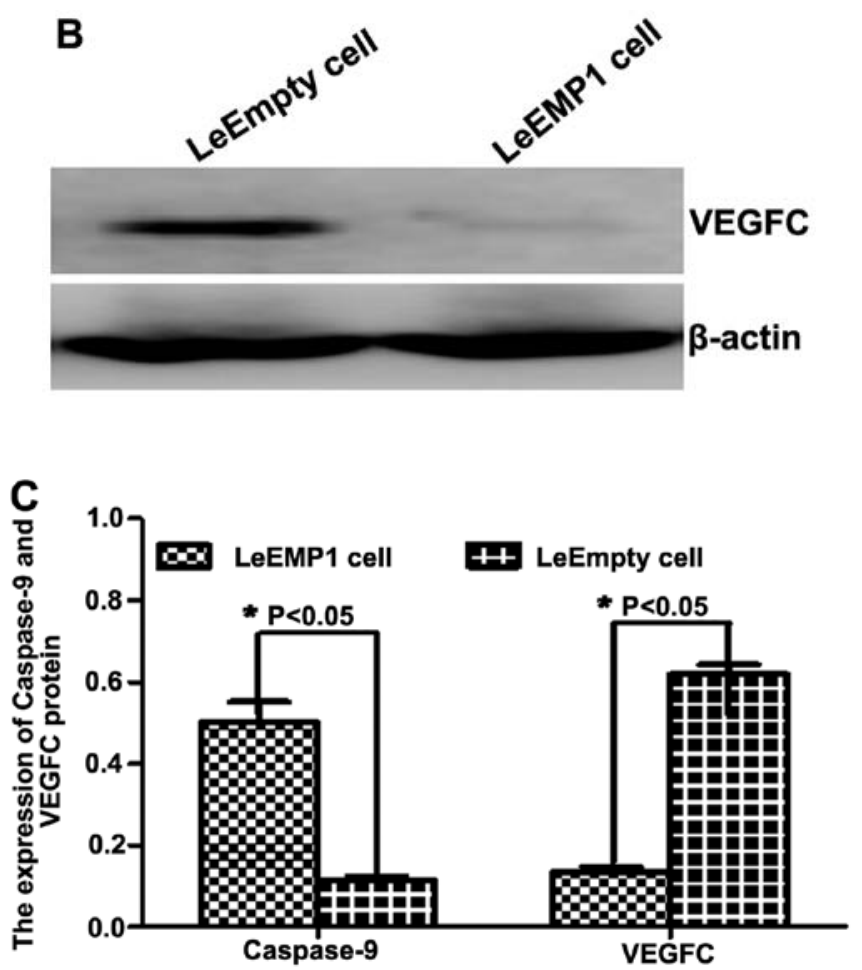

Figure 8. Effects of EMP1 overexpression on caspase-9 and VEGFC. (A) Sample blot for caspase-9 and actin (loading control) of gastric cancer cells transfected with LeEMP1 and LeEmpty; (B) Sample blot for VEGFC and actin; (C) Quantification of caspase-9 and VEGFC expression LeEMP1 and LeEmpty cells. ${ }^{*} \mathrm{P}<0.05$.

positive patients had a significantly higher 5 -year overall survival rate than patients with undetectable EMP1 expression. Thus, combining information from the TNM classification system and EMP1 expression scores may provide valuable information for clinicians regarding prognosis, prediction of disease severity and selection of treatment regimens.

Furthermore, in vitro experiments demonstrated for the first time that gastric cancer cells with high EMP1 expression had significantly weakened proliferation, significantly increased apoptosis, markedly increased caspase -9 and reduced VEGFC protein levels. Previously, overexpression of EMP1 in an esophageal cancer cell line slowed esophageal cancer cell growth and yielded fewer S-phase cells and more G1-phase cells (26). Together with our findings, these data suggest that low levels of EMP1 affect cellular processes that are abnormally regulated in cancer. Mitochondria are not only the site of cellular respiration and oxidative phosphorylation, but also the regulation center of apoptosis. Cytochrome C released from mitochondria to the cytoplasm associates with apoptotic protease activating factor (Apaf-1) to form a multiservice complex in the presence of deoxyribonucleotide triphosphate (dNTP) (31). This complex interacts with procaspase-9 to form an apoptosome and, following dimerization, results in autoactivation of caspase-9. This activated caspase-9 stimulates other caspases, such as caspase-3 and caspase-7, culminating in apoptosis via signaling cascades (32-34). We found in this study that high expression of EMP1 is associated with significantly higher expression of caspase-9 protein, implicating a mitochondrial apoptosis pathway in EMP1induced apoptosis.

VEGF is a member of the platelet-derived growth factor (PDGF) family and is the most important vascular endothelial growth-stimulating factor during tumor angiogenesis. VEGFC is a recently identified member of the VEGF family, which promotes the proliferation of endothelial cells, increases vascular permeability, and functions as a key factor in tumor angiogenesis, invasion and metastasis $(35,36)$. We found in this study that overexpression of EMPI is associated with a significant decrease in VEGFC expression. This finding suggests that EMP1 may inhibit tumor angiogenesis by suppressing VEGFC expression and hence tumor metastasis.

In summary, we demonstrated that EMP1 protein levels were significantly reduced in gastric carcinoma and were associated with tumor invasion, lymph node metastasis, clinical stage and cell differentiation. EMP1 is involved in a number of biological processes including proliferation, apoptosis, invasion and metastasis of gastric cancer. Given the complexity of carcinogenesis, further research is needed to understand the molecular mechanism underlying EMP1 regulation of this process. Our findings identify a novel potential therapeutic target for gastric cancer and suggest EMP1 may be a reliable biomarker for prognosis of gastric cancer.

\section{References}

1. Hofmockel G: Molecular genetic principles of tumor development and progression. Urologe A 39: 212-213, 2000.

2. de Martel C, Forman D and Plummer M: Gastric cancer: epidemiology and risk factors. Gastroenterol Clin North Am 42: 219-240, 2013.

3. Dimofte G, Tarcoveanu E, Taraşi M, Panait C, Lozneanu G, Nicolescu S, Porumb V and Grigoraş O: Mean number of lymph nodes in colonic cancer specimen: possible quality control index for surgical performance. Chirurgia (Bucur) 106: 759-764, 2011.

4. Fleming M, Ravula S, Tatishchev SF and Wang HL: Colorectal carcinoma: pathologic aspects. J Gastrointest Oncol 3: 153-173, 2012.

5. Lai S, Wang G, Cao X, Li Z, Hu J and Wang J: EMP-1 promotes tumorigenesis of NSCLC through PI3K/AKT pathway. J Huazhong Univ Sci Technolog Med Sci 32: 834-838, 2012.

6. Wang HT, Liu ZH, Wang XQ and Wu M: Effect of EMP-1 gene on human esophageal cancer cell line. Ai Zheng 21: 229-232, 2002.

7. Lee HS, Sherley JL, Chen JJ, Chiu CC, Chiou LL, Liang JD, Yang PC, Huang GT and Sheu JC: EMP-1 is a junctional protein in a liver stem cell line and in the liver. Biochem Biophys Res Commun 334: 996-1003, 2005.

8. Kasher R, Bajayo A, Gabet Y, Nevo N, Fridkin M, KatchalskiKatzir E, Kohen F and Bab I: Restrain of bone growth by estrogen-mimetic peptide-1 (EMP-1): a micro-computed tomographic study. Peptides 30: 1181-1186, 2009.

9. Bozec A, Peyrade F and Milano G: Molecular targeted therapies in the management of head and neck squamous cell carcinoma: recent developments and perspectives. Anticancer Agents Med Chem 13: 389-402, 2013. 
10. Suzuki K, Nakamura K, Kato K, Hamada $\mathrm{H}$ and Tsukamoto $\mathrm{T}$ : Exploration of target molecules for prostate cancer gene therapy. Prostate 67: 1163-1173, 2007.

11. Turashvili G, Bouchal J, Ehrmann J, Fridman E, Skarda J and Kolar Z: Novel immunohistochemical markers for the differentiation of lobular and ductal invasive breast carcinomas. Biomed Pap Med Fac Univ Palacky Olomouc Czech Repub 151: 59-64, 2007.

12. Muller PY, Janovjak H, Miserez AR and Dobbie Z: Processing of gene expression data generated by quantitative real-time RT-PCR. Biotechniques 32: 1372-1379, 2002.

13. Ranganathan V and De PK: Western blot of proteins from Coomassie-stained poly-acrylamide gels. Anal Biochem 234: 102-104, 1996

14. van Meerloo J, Kaspers GJ and Cloos J: Cell sensitivity assays: the MTT assay. Methods Mol Biol 731: 237-245, 2011.

15. Rasola A and Geuna M: A flow cytometry assay simultaneously detects independent apoptotic parameters. Cytometry 45 $151-157,2001$

16. Kramer N, Walzl A, Unger C, Rosner M, Krupitza G, Hengstschläger $\mathrm{M}$ and Dolznig $\mathrm{H}$ : In vitro cell migration and invasion assays. Mutat Res 752: 10-24, 2013.

17. Richards RJ: Responsibility for statistical analyses. Endocr Pract 9: $329,2003$.

18. Taylor V, Welcher AA, Program AE and Suter U: Epithelial membrane protein-1, peripheral myelin protein 22 , and lens membrane protein 20 define a novel gene family. J Biol Chem 270: 28824-28833, 1995.

19. Lobsiger CS, Magyar JP, Taylor V, Wulf P, Welcher AA, Program AE and Suter U: Identification and characterization of a cDNA and the structural gene encoding the mouse epithelial membrane protein-1. Genomics 36: 379-387, 1996.

20. Wulf $P$ and Suter U: Embryonic expression of epithelial membrane protein 1 in early neurons. Brain Res Dev Brain Res 116: 169-180, 1999.

21. Zoidl G, Blass-Kampmann S, D'Urso D, Schmalenbach C and Müller HW: Retroviral-mediated gene transfer of the peripheral myelin protein PMP22 in Schwann cells: modulation of cell growth. EMBO J 14: 1122-1128, 1995.

22. Jetten AM and Suter U: The peripheral myelin protein 22 and epithelial membrane protein family. Prog Nucleic Acid Res Mol Biol 64: 97-129, 2000.

23. Yu XM, Li CW, Li YY, Liu J, Lin ZB, Li TY, Zhao L, Pan XL, Shi L and Wang de Y: Down-regulation of EMP1 is associated with epithelial hyperplasia and metaplasia in nasal polyps. Histopathology 63: 686-695, 2013.

24. Gnirke AU and Weidle UH: Investigation of prevalence and regulation of expression of progression associated protein (PAP). Anticancer Res 18: 4363-4369, 1998.
25. Zhang J, Cao W, Xu Q and Chen WT: The expression of EMP1 is downregulated in oral squamous cell carcinoma and possibly associated with tumour metastasis. J Clin Pathol 64: 25-29, 2011.

26. Wang HT, Kong JP, Ding F, Wang XQ, Wang MR, Liu LX, $\mathrm{Wu} \mathrm{M}$ and Liu $\mathrm{ZH}$ : Analysis of gene expression profile induced by EMP-1 in esophageal cancer cells using cDNA Microarray. World J Gastroenterol 9: 392-398, 2003.

27. Isobe T, Hashimoto K, Kizaki J, Miyagi M, Aoyagi K, Koufuji K and Shirouzu K: Characteristics and prognosis of gastric cancer in young patients. Oncol Rep 30: 43-49, 2013.

28. Lee HS, Lee HK, Kim HS, Yang HK and Kim WH: Tumour suppressor gene expression correlates with gastric cancer prognosis. J Pathol 200: 39-46, 2003.

29. Chen Y and Mou L: A risk score system to preoperatively predict TNM stages in gastric cancer. Am J Clin Oncol 34: 130-134, 2011.

30. Jiexian J, Xiaoqin X, Lili D, Baoguo T, Ting S, Xianwen Z and Cunzhi H: Clinical assessment and prognostic evaluation of tumor markers in patients with gastric cancer. Int J Biol Markers 28: 192-200, 2013.

31. Sen S, Kawahara B and Chaudhuri G: Mitochondrial-associated nitric oxide synthase activity inhibits cytochrome c oxidase: implications for breast Cancer. Free Radic Biol Med 57: 210-220, 2013.

32. Zhang JM, Wang HC, Wang HX, Ruan LH, Zhang YM, Li JT, Tian S and Zhang YC: Oxidative stress and activities of caspase-8, -9 , and -3 are involved in cryopreservation-induced apoptosis in granulosa cells. Eur J Obstet Gynecol Reprod Biol 166: 52-55, 2013

33. Johnson CR and Jarvis WD: Caspase-9 regulation: an update. Apoptosis 9: 423-427, 2004.

34. Fearnhead HO, Rodriguez J, Govek EE, Guo W, Kobayashi R, Hannon G and Lazebnik YA: Oncogene-dependent apoptosis is mediated by caspase-9. Proc Natl Acad Sci USA 95: 13664-13669, 1998.

35. Xie LX, Zhai TT, Yang LP, Yang E, Zhang XH, Chen JY and Zhang $\mathrm{H}$ : Lymphangiogenesis and prognostic significance of vascular endothelial growth factor $\mathrm{C}$ in gastro-oesophageal junction adenocarcinoma. Int J Exp Pathol 94: 39-46, 2013.

36. Zhang Y, Meng X, Zeng H, Guan Y, Zhang Q, Guo S, Liu X and Guo Q: Serum vascular endothelial growth factor-C levels: a possible diagnostic marker for lymph node metastasis in patients with primary non-small cell lung cancer. Oncol Lett 6: 545-549, 2013. 